\title{
Overview of Langerhans Cell Histiocytosis among Children
}

\author{
ALIA AHMAD ${ }^{1}$, MAHVISH HUSSAIN², SHAZIA YASEEN ${ }^{3}$, ASMA MUSHTAQ ${ }^{4}$, AYESHA BIBI ${ }^{5}$, IQBAL HUSSAIN DOGAR ${ }^{6}$, \\ FAUZIA SHAFI KHAN ${ }^{7}$ \\ ${ }^{1}$ Associate Professor Paediatric Haematology/Oncology, The Children's Hospital Lahore Pakistan \\ ${ }^{2}$ Assistant Professor Paediatric Histopathology, The Children's Hospital Lahore Pakistan \\ ${ }^{3}$ Assistant Professor Paediatric Haematology, The Children's Hospital Lahore Pakistan \\ ${ }^{4}$ Assistant Professor Paediatric Ophthalmology, The Children's Hospital Lahore Pakistan \\ ${ }^{5}$ Fellow Paediatric Haematology/Oncology, The Children's Hospital Lahore Pakistan \\ ${ }^{6}$ Associate Professor Paediatric Radiology, The Children's Hospital Lahore Pakistan \\ ${ }^{7}$ Associate Professor Paediatric Haematology, The Children's Hospital Lahore Pakistan \\ Correspondence to Dr. Alia Ahmad, E-mail: alia_ahmad99@yahoo.com, Cell 0334-4081996
}

\begin{abstract}
Aim: To analyze clinical manifestations, course and outcome of Langerhans Cell Histiocytosis in children in resource limited settings lacking salvage therapy.

Study design: Observational retrospective study

Place and duration of study: Department of Haematology/Oncology, The Children's Hospital, Lahore Pakistan from $1^{\text {st }}$ January 2011 to $31^{\text {st }}$ December 2018.

Methodology: Sixty-five patients with age range from $<1$ to 8 years included analysing their age, gender, clinical classification, course of therapy and outcome. The major treatment was composed of either prednisolone and vinblastine or cytarabine pulses.

Results: There were $59 \%$ males and $41 \%$ females. Forty-seven $(72 \%)$ patients presented with multi system-LCH with $49 \%$ Risk Organ involvement. Most of them 42 (65\%) had bone lesions while 15patients (23\%) presented with central nervous system involvement. Forty patients $(61 \%)$ have completed treatment, $11(17 \%)$ left against medical advice and $12(18 \%)$ patients expired due to progressive disease and worsening infection. Only 2 patients were put on palliation with progressive brain parenchyma disease. 22 patients $(34 \%)$ had reactivations of disease requiring therapy for more than one-year ( $p$-value $=0.06$ ), while $15(23 \%)$ patients received two cycles of initiation therapy before continuation therapy started. The treatment initiated $>6$ months after the onset of symptoms in 48 (74\%) patients.

Conclusion: Early diagnosis and timely initiation of therapy are of utmost importance to reduce mortality and morbidity. There is a dire need of social support to reduce treatment abandonment in low-middle-income countries LMIC.

Keywords: Paediatric Langerhans cell histiocytosis, Resource-limited settings, Delayed diagnosis, Abandonment
\end{abstract}

\section{INTRODUCTION}

Langerhans cell histiocytosis $(\mathrm{LCH})$ is a rare histiocytic disorder, with myriad of clinical features from unifocal bony lesion to widespread disease and life-threatening sequelae. ${ }^{1,2}$ The incidence of $\mathrm{LCH}$ is $2-9$ /million per year inchildren $^{1,2}$, with peak diagnosis is around 1-4 years. ${ }^{2,3}$ Children at all ages can suffer from $\mathrm{LCH}$; however, multisystem disease is more common among infants. This can involve not only soft tissues but also the bony compartment of particularly head and neck region. In addition, patients can have manifestations in skin, lymphoid tissue, bone marrow and central nervous system (CNS) ${ }^{1-4}$

Langerhans cell histiocytosis is considered a neoplasm of myeloid origin having a clonal proliferation of CD1a and CD207 cells with BRAF mutations. 25\% cases have been reported to have mutations in MAPK/ERK pathway. ${ }^{3}$ The disease has been reclassified from an immune disorder to a neoplasm and led to the development of new targeted therapies. Current treatment regimens provide cure in $80 \%$ of these patients. However, disease recurrence has been observed in $30-50 \%$ of the patients. ${ }^{2}$ Barres et al also suggested $\mathrm{LCH}$ to be considered an inflammatory myeloid neoplasia. ${ }^{5}$ Currently, $\mathrm{LCH}$ is categorized into three distinct groups according to the site and system involvement. There can be single system involvement with a single site as well as multiple sites. In addition, multiple systems can be involved simultaneously. However majority patients have involvement of a single system. Skeletal system is predominantly involved in single system (SS). Multi system LCH (MS-LCH)may present either with or without organ involvement. Skin, bones, lymph nodes, and the pituitary gland are included in lowrisk, whereas bone marrow, liver, spleen are classified as high-risk organs. ${ }^{4}$ Approximately half of MS-LCH patients have more than one risk organ (RO) involvement. ${ }^{6}$

Various studies have been done to determine the clinical spectrum, outcome, and prognostic factors of $\mathrm{LCH}$ worldwide but there is scarce data available from Pakistan. This study aims to highlight the challenges faced in treating this rare paediatric disease with lack of salvage therapies in the form of targeted therapies like nucleoside analogues and BRAF inhibitors for long term cure and reduced reactivation rates.

\section{PATIENTS AND METHODS}

This observational retrospective study was done at Department of Haematology/Oncology, Children's Hospital \& $\mathrm{ICH}$, Lahore Pakistan from $1^{\text {st }}$ January 2011 to

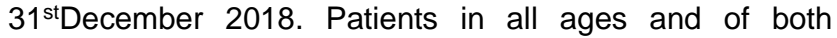
genders were included. Each patient was thoroughly 
investigated for his complete blood count, liver and renal function tests, serum albumin, ferritin, coagulation profile, $\mathrm{LDH}$, skeletal surveys, ultrasonography of abdomen, radiographs of chest and skull. In addition, tissue biopsy followed by its immunohistochemistry with CD1a and S100 wherever applicable along with bone marrow biopsy were also done. Complex radiological investigations including CT scan, MRI of brain and hormonal assays if required, were also carried out. The first line treatment composed of intravenous vinblastine and oral steroids as initiation therapy for 6-12 weeks and Continuation phase for 6-12 months and for refractory cases intravenous cytarabine pulses $120-150 \mathrm{mg} / \mathrm{m}^{2}$ for 5 days every 3-4 weeks for 6 months to 1 year. The salvage therapies in the form of adenosine analogues (clofarabine and cladribine), BRAF/MEK inhibitors and allogenic stem cell transplantation were not available due to financial constraints. The data was entered and analyzed through SPSS 20.

\section{RESULTS}

Thirty-eight (59\%) were males and $27(41 \%)$ were females with $\mathrm{M}: \mathrm{F}$ ratio of $1.4: 1$ (Fig. 1). Among total, 49/65(75\%) were $>2$ years and $25 \%<2$ Years old (Table 1). Time interval to reach the clinical diagnosis was more than 6 months in 48 patients (74\%). At the initial presentation, majority of the patients $47(72 \%)$ had multi system involvement. Whereas multifocal bone involvement was present in 27 patients (42\%), and unifocal bone involvement was seen in 29 patients (45\%). Risk organ involvement was present in $32(45 \%)$ children. Patients presented with CNS involvement were only $15(23 \%)$. Regarding treatment majority of the patients $40(61 \%)$ had completed treatment, whereas 11 of them (17\%) abandoned treatment during therapy and 12(18\%) children expired. Palliative therapy was given to 2 patients with progressive brain parenchymal disease (Fig. 2). Twentyone $(32 \%)$ had reactivation of disease with therapy for more than one year ( $p$-value=0.06) [Table 2]. Fifteen $(23 \%)$ were given two cycles of initiation therapy due to inadequate response before continuation therapy started. The most common skin manifestations in our study were red scaly popular lesions, seborrheic dermatitis, petechiae with purpuric macules and vesiculopustular lesions with generalized distribution. The diagnosis was confirmed by histopathology and immunohistochemistry of tissue biopsies (Figs. 3-5)

Fig. 1: Frequency of gender

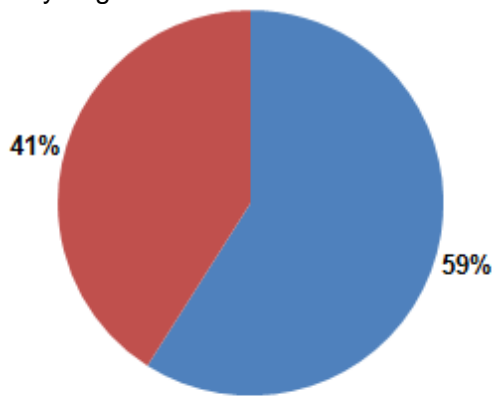

Males $n$ Females

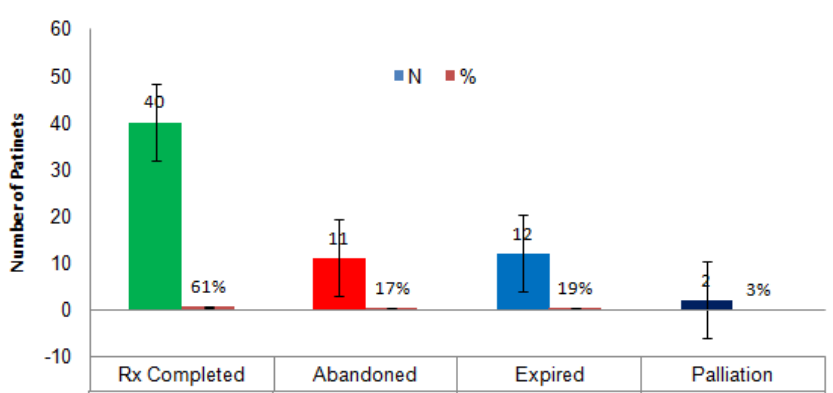

Fig. 2: Frequency of outcome

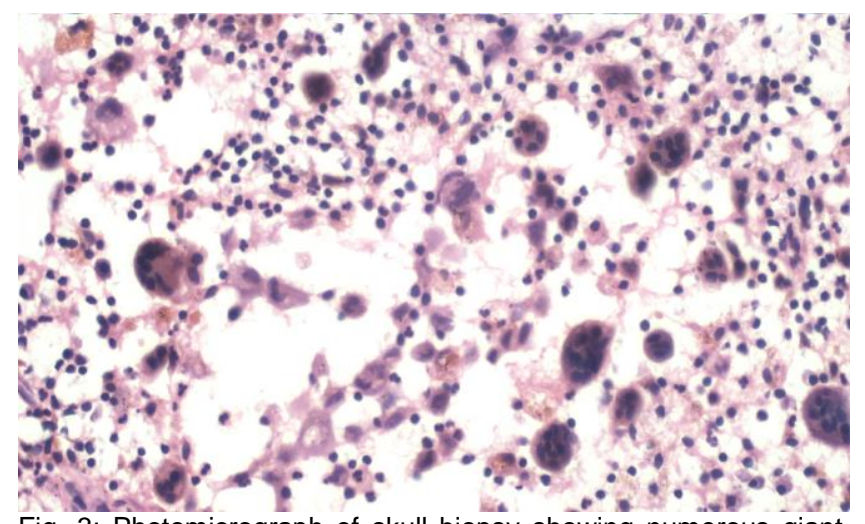

Fig. 3: Photomicrograph of skull biopsy showing numerous giant cells, inflammatory infiltrate and histiocytes

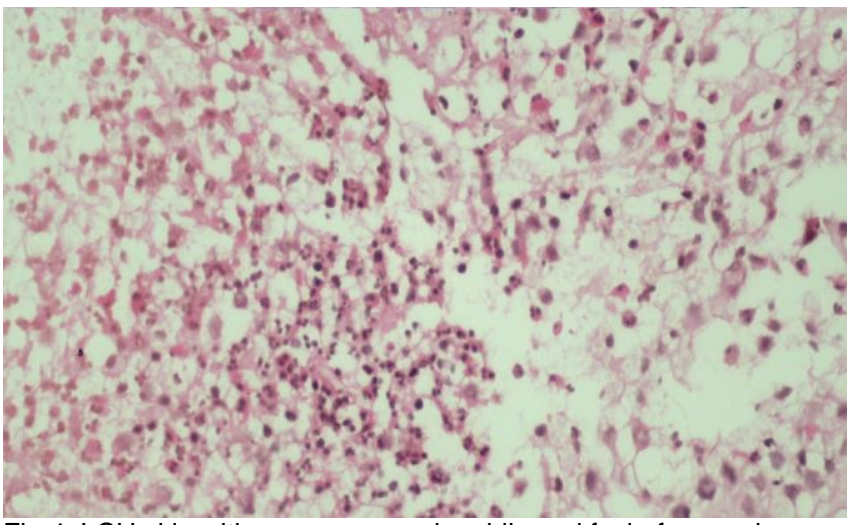

Fig 4: LCH skin with numerous eosinophils and foci of necrosis.

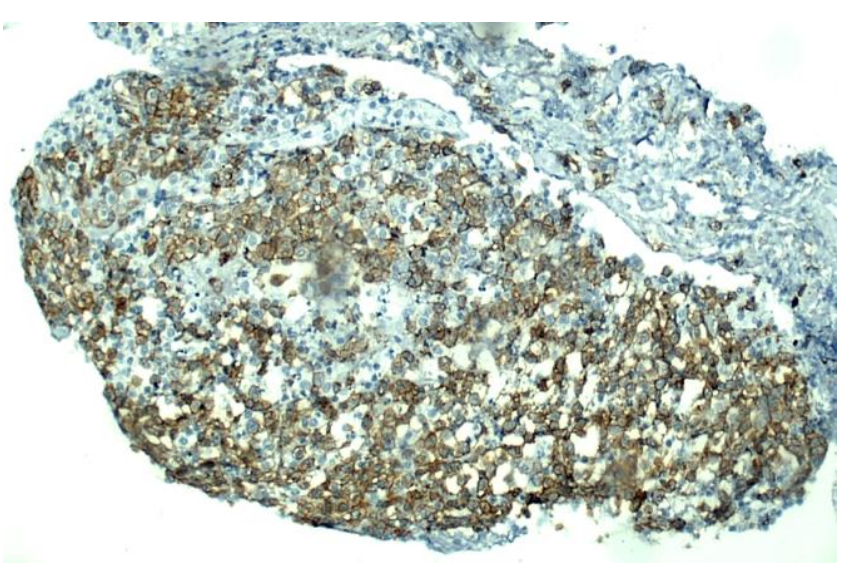


Fig 5: LCH lymph node showing atypical histiocytic proliferation (CD1a X 200)

Table 1: Clinical Characteristics

\begin{tabular}{|c|c|c|c|}
\hline Variable & No. & $\%$ & $P$ value \\
\hline \multicolumn{4}{|l|}{ Age (years) } \\
\hline$<2$ & 16 & 25.0 & \multirow{2}{*}{0.000} \\
\hline$>2$ & 49 & 75.0 & \\
\hline \multicolumn{4}{|l|}{ Classification } \\
\hline Single system (SS) & 18 & 28.0 & \multirow{2}{*}{0.217} \\
\hline Multisystem (MS) & 47 & 72.0 & \\
\hline \multicolumn{4}{|l|}{ Lytic lesions } \\
\hline Present & 42 & 65.0 & \multirow{2}{*}{0.218} \\
\hline Not present & 23 & 35.0 & \\
\hline \multicolumn{4}{|l|}{ Bone lesions } \\
\hline Multifocal & 27 & 42.0 & \multirow{3}{*}{0.213} \\
\hline Unifocal & 29 & 44.0 & \\
\hline NA & 9 & 14.0 & \\
\hline Risk organ + & 32 & 49.0 & \multirow{2}{*}{0.000} \\
\hline Not involved & 33 & 51.0 & \\
\hline CNS lesions & 15 & 23.0 & \multirow{2}{*}{0.061} \\
\hline No CNS lesions & 60 & 77.0 & \\
\hline
\end{tabular}

Table 2: Clinical Course

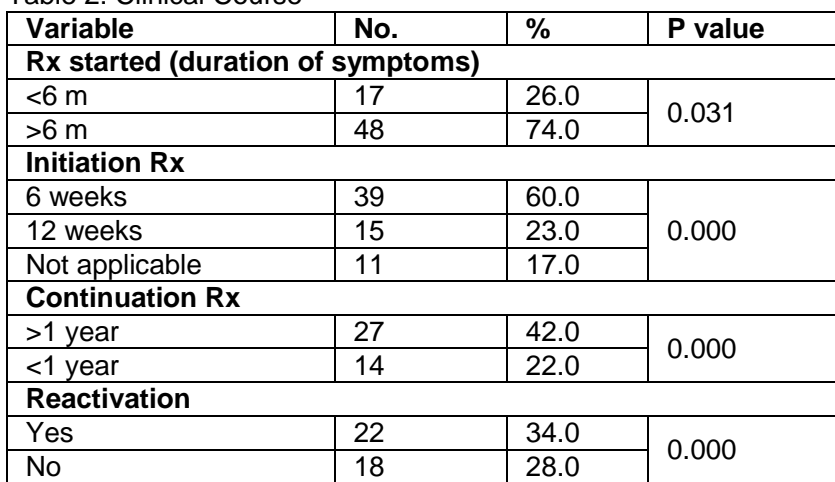

$\mathrm{P}$-value measured for outcome and the clinical course and characteristics.

\section{DISCUSSION}

This study has given an overview of paediatric LCH in resource limited settings in a public sector hospital in Pakistan with $25 \%$ of children presenting at ages less than 2 years with male preponderance. In contrast to Narula et $\mathrm{al}^{7}$, who noticed median age of the patients as 36 months in their population. However male predominance was observed in their study group like our study. Kim et $\mathrm{al}^{6}$ also observed median age of the patients as 65 months in their population.

In our study bone was involved in $65 \%$ children with $42 \%$ having multifocal bony lesions and reactivation in 34\% cases (Table 1). Like Narula et $\mathrm{al}^{8}$, who also observed predominantly involvement of bones and skull. However, Dhar et $\mathrm{al}^{9}$, in contrast observed mainly involvement of skin followed by bones.

Prognosis of $\mathrm{LCH}$ is highly dependent on the involvement of body systems. Single-system LCH has a better prognosis with a $100 \% 5$-year survival and $<20 \%$ recurrence risk whereas MS-LCH has more risk of relapses and complications requiring more aggressive management. ${ }^{10}$ In our study, majority patients $(72 \%)$ had MS-LCH at initial presentation and only $28 \%$ presented with SS-LCH with $84 \%$ survival, two abandoned treatment and one expired (Table 1 ). In contrast $54 \%$ of MS-LCH completed treatment and are well and the rest either abandoned treatment, put on palliation, or expired due to progressive disease and complications of treatment.In contrast, Dhar et $\mathrm{al}^{9}$ showed only $32 \%$ of the total patients with multisystem $\mathrm{LCH}$ at the time of presentation. Complications developed in few patients resulted in mortality of $8 \%$ in their population group. ${ }^{10}$

McClain et al $^{11}$ noticed involvement of CNSin $23 \%$ of cases including diabetes insipidus and parenchymal brain lesions. Out of their total population, 60\% completed the treatment and two cases were given palliative treatment due to aggressive brain parenchymal disease. However, only three patients abandoned treatment. CNS lesions range from granulomatous, non-granulomatous with or without calcification and atrophy and neurodegeneration, best defined by MRI brain. ${ }^{11,12}$

In our study, among the children less than 2 years $38 \%$ achieved complete remission, 37\% abandoned and $25 \%$ expired as demonstrated to be higher risk when presented at younger age. In the present study, only $49 \%$ of the total children had risk organ involvement with only one third able to complete treatment and rest were expired or abandoned treatment. In contrast,Narula et $\mathrm{al}^{7}$ showed few cases with $\mathrm{RO}+$ and benefited with longer maintenance of 18 months in addition to oral etoposide for 21 days in each 28 days cycle. Gadner et al also described high mortality rate associated with $\mathrm{MS}-\mathrm{LCH}$ with $\mathrm{RO}+$. However, they observed that intensified treatment regimens can be beneficial to the patients in reducing the mortality rate. ${ }^{13}$

In the present study, a gap of more than 6 months was observed between the onset of disease symptoms and the start of therapy in $74 \%$ of the cases. The reason of this gap was diagnostic delay as the patients usually presented with cutaneous and other manifestations of less severe intensity. That resulted in delay in initiation of therapy. Initiation RX was given for 12 weeks in $23 \%$ cases based on early response and continuation treatment was extended to more than one year in almost half of the cases. Similarly, Dhar et al faced the same problem of diagnostic delay especially in patients presenting with SS-LCH. Such patients were misdiagnosed as seborrheic dermatitis in $68 \%$ of the total cases. ${ }^{9}$

Similarly, Uppal et al $^{14}$ described the mean time interval to reach the final diagnosis of 9 months with range of 1-30 months. Meanwhile, these patients received symptomatic therapy for many months without any improvement. Therefore, the threshold to suspect $\mathrm{LCH}$ should be reduced, prompting timely management and better possible outcome. As LCH is an uncommon disease and should be suspected in children having unexplained clinical features of lung, CNS, skin, and bone delaying the final diagnosis and consequently resulting in more complications. ${ }^{15}$

Kim et $\mathrm{al}^{16}$ showed that majority of their patients $(69.5 \%)$ had SS-LCH, followed by MS-LCH without involvement risk organs MS-RO- in $14.1 \%$ and $\mathrm{MS}-\mathrm{RO}+$ in $16.4 \%$ cases with 5 -year overall survival (OS) rates in these groups were $99.8 \%, 98.4 \%$, and $77.0 \%$, respectively and likewise increased 5-year reactivation rates from $17.9 \%, 33.5 \%$, and $34.3 \%$.Conversely, in our study in SS$\mathrm{LCH}$ reactivation is $28 \%$, in MS- $\mathrm{LCH} 34 \%$ and $33 \%$ in the 
total cases ( $p$ value $<0.05$ ). These reactivations are usually less severe in extent and severity than the primary disease and thus did not result in high mortality. Continued efforts are needed to decrease reactivations, but unfortunately the toxicity of the treatment of $\mathrm{LCH}$ cannot be ignored. ${ }^{17,18} \mathrm{In}$ $\mathrm{LCH}$ reactivation is not uncommonwith relapses in $20 \%$ to $50 \%$ of patients. Generally, in both groups of patients with low-risk SS-LCH having reactivation of multifocal bone disease or low-risk MS- LCH/RO-, reactivations happen in approximately one-third of patients with good response to second-line regimens. Patients with high-risk disease MS$\mathrm{LCH} \mathrm{RO+and} \mathrm{those} \mathrm{with} \mathrm{inadequate} \mathrm{response} \mathrm{to} \mathrm{standard}$ treatment protocols have poor survival, though they respond to intense regimens with cladribine and high dose cytarabine pulses, stem cell rescue and BRAF inhibitors. ${ }^{2,19}$ Although survival is highly dependent on whether risk organs are involved or not, tremendous progress has been made in the management of $\mathrm{LCH}$, with significant improvement of survival in high risk $\mathrm{LCH}$ up to around $90 \% .^{17}$

Our study showed that among patients having MS$\mathrm{RO}+(\mathrm{n}=32,49 \%)$ of total cohort only $34 \%$ completed treatment and are doing well. Of the remaining, $32 \%$ abandoned treatment andthe rest of $34 \%$ expired. The patients without RO involvement $88 \%$ completed treatment and are well, one patient expired, one abandoned and two patients were put on palliation due to advanced disease and poor response to treatment regimens available in the resource limited settings.Jain et $\mathrm{al}^{15}$ observed with a cohort of $28 \mathrm{LCH}$ patients that majority of their patients achieved complete remission with only around $18 \%$ of them relapsed and were in remission after second line treatment protocol and only6/28 patients had progressive disease with 7\% abandonment and 14\% expiries and 7\% lost to follow up.In the present study also showed the same problem of abandonment of treatment. This poses one of the greatest challenges for providing standard of care therapies for childhood canceraffecting up to $50-60 \%$ of children as are the other challenges like lack of health education, reduced access to healthcare, and poor socioeconomic environment causing delayed diagnosis in Low-middle-income LMIC countries, augmented by insufficient number of populationbased cancer registries in the region. ${ }^{19-21}$

\section{CONCLUSION}

To improve the long-term survival of these LCH patients in resource limited settings it is imperative to ensure early diagnosis, efficient referral systems, effective psychosocial support to minimize abandonment and efficient supportive care to reduce morbidity and mortality.

\section{REFERENCES}

1. Stålemark H, Laurencikas E, Karis J, Gavhed D, Fadeel B, Henter Jl. Incidence of Langerhans cell histiocytosis in children: a population-based study. Pediatr Blood Cancer 2008;51(1):76-81.

2. Jezierska M, Stefanowicz J, Romanowicz G, Koiak W and Lange M.Langerhans cell histiocytosis in children - a disease with many faces. Recent advances in pathogenesis, diagnostic examinations and treatment. Postepy Dermatol Alergol 2018; 35(1):6-17.
3. Monsereenusorn C, Rodriguez-Galindo C. Clinical characteristics, and treatment of Langerhans cell histiocytosis. Hematol Oncol Clin 2015;29(5):853-73.

4. Krooks J, Weatherall AG. Langerhans cell histiocytosis in children: History, classification, pathobiology, clinical manifestations, and prognosis. I Ame Acad Dermatol 2018;78(6):1035-44

5. Berres ML, Merad M, Allen CE. Progress in understanding the pathogenesis of Langerhans cell histiocytosis: back to Histiocytosis X. Br J Haematol 2015;169(1):3-13.

6. Kim BE, Koh KN, Suh JK, Im HJ, Song JS, Lee JW, et al. Clinical features, and treatment outcomes of Langerhans cell histiocytosis: a nationwide survey from Korea histiocytosis working party. J Pediatr Hematol Oncol 2014;36(2):125-33.

7. Narula G, Pradhan ND, Arora B, Banavali SD. Treatment of Langerhans cell histiocytosis with a modified risk-adapted protocol - experience from a tertiary cancer institute in India. Pediatr Blood Cancer 2018;65(8): e27028.

8. Narula G, Bhagwat R, Arora B, Banavali SD, Pai SK, Nair $\mathrm{CN}$, et al. Clinico-biologic profile of Langerhans cell histiocytosis: a single institutional study. Indian J Cancer 2007;44(3):93-8.

9. Dhar S, Srinivas SM, Dhar S, Basu S, Banerjee R, Malakar $\mathrm{R}$, et al. Langerhans cell histiocytosis in children: a retrospective case series of 126 cases. Pediatr Dermatol 2020;37(6):1085-9.

10. Haupt R, Nanduri V, Calevo MG, Bernstrand C, Braier JL, Broadbent $\mathrm{V}$, et al. Permanent consequences in Langerhans cell histiocytosis patients: a pilot study from the Histiocyte Society - Late Effects Study Group. Pediatr Blood Cancer 2004;42(5):438-44

11. McClain KL, Picarsic J, Chakraborty R, Zinn D, Lin H, Abhyankar $\mathrm{H}$, et al. CNS Langerhans cell histiocytosis: Common hematopoietic origin for $\mathrm{LCH}$-associated neurodegeneration and mass lesions. Cancer 2018;124(12):2607-20.

12. Grois N, Fahrner B, Arceci RJ, Henter JI, McClain K, Lassmann $\mathrm{H}$, et al. Central nervous system disease in Langerhans cell histiocytosis. J Pediatr 2010;156(6):873-81.

13. Gadner H, Grois N, Pötschger U, Minkov M, Aricò M, Braier $\mathrm{J}$, et al. Improved outcome in multisystem Langerhans cell histiocytosis is associated with therapy intensification. Blood 2008:1;111(5):2556-62.

14. Uppal P, Bothra M, Seth R, lyer V, Kabra SK. Clinical profile of Langerhans cell histiocytosis at a tertiary centre: a prospective study. Indian J Pediatr 2012:79(11):1463-7.

15. Jain A, Kumar S, Aggarwal P, Kumar M, Gupta V. Langerhans cell histiocytosis: an enigmatic disease. South Asian J Cancer 2019;8(3):183.

16. Kim BE, Koh KN, Suh JK, Im HJ, Song JS, Lee JW, et al. Clinical features, and treatment outcomes of Langerhans cell histiocytosis: a nationwide survey from Korea histiocytosis working party. J Pediatr Hematol Oncol 2014;36(2):125-33.

17. Abla O, Rollins $B$, Ladisch S. Langerhans cell histiocytosis: progress and controversies. $\mathrm{Br} J$ Haematol 2019; 187(5):559-62.

18. Gadner H, Minkov M, Grois N, Pötschger U, Thiem E, Aricò $M$, et al. Therapy prolongation improves outcome in multisystem Langerhans cell histiocytosis. Blood 2013;121(25):5006-14.

19. Rodriguez-Galindo C, Friedrich P, Morrissey L, Frazier L. Global challenges in pediatric oncology. Curr Opinion Pediatr 2013;25(1):3-15.

20. Sitaresmi MN, Mostert S, Schook RM, Veerman AJ. Treatment refusal and abandonment in childhood acute lymphoblastic leukemia in Indonesia: an analysis of causes and consequences. Psycho-Oncology 2010;19(4):361-7.

21. Bonilla M, Rossell N, Salaverria C, Gupta S, Barr R, Sala A, et al. Prevalence, and predictors of abandonment of therapy 
among children with cancer in El Salvador. Int $\mathrm{J}$ Cancer 2009;125(9):2144-6. 